\title{
119
}

\section{Planning and Implementing User-Centred Design Using ISO 13407}

\author{
Nigel Bevan and Ian Curson \\ National Physical Laboratory, Usability Services \\ Teddington, Middlesex, TW11 0LW, UK \\ Nigel.Bevan@npl.co.uk, Ian.Curson@npl.co.uk
}

\begin{abstract}
The tutorial introduces participants to the forthcoming International Standard "Human centred design processes for interactive systems" (ISO CD 13407), and gives an overview of practical techniques which support the processes outlined in the standard. The INUSE consortium of usability practitioners has developed a set of core techniques to support the human-centred design process, selected on the basis of their applicability, maturity, stability, availability, and cost-effectiveness. The tutorial explains the basis for choosing appropriate techniques, and gives an overview of each method. The techniques are divided into three categories: Planning, Early Lifecycle and Late Lifecycle. The methods covered are: Planning - ISO 13407 checklist, usability context analysis, usability maturity assessment; Early lifecycle - guides and standards, rapid prototyping, usability inspection methods; Late lifecycle performance measurement method, user satisfaction, adherence to guides and standards.
\end{abstract}

KEY WORDS: User-centred design, usability evaluation, standards, usability engineering, software engineering

\section{OBJECTIVES}

Many organisations now recognise the need for usability in interactive systems, and the benefits that usable systems deliver. But guidance about how to "do" usability tends to be technique-centred, concentrating on specific approaches for designing or evaluating systems. How can organisations at different levels of usability maturity, and with different criteria for usable systems, discover how to improve the usability of their systems?

ISO CD 13407 advocates a process-oriented approach to usability, whereby usable systems are achieved as the result of a human-centred design process. The standard provides a framework for applying human-centred design and evaluation techniques, and is intended to supplement existing lifecycle models.
Different organisations are at different levels of usability maturity - from not recognising usability as an issue, to having processes in place which ensure the development of consistently usable systems. Organisations can integrate the principles of ISO CD 13407 into their existing development process incrementally, to achieve an appropriate maturity level.

ISO CD 13407 specifies types of activity to be performed during the development of an interactive system, but does not demand nor recommend particular techniques or methods. The INUSE consortium of usability practitioners has developed a set of core techniques to support the human-centred design process, selected on the basis of their applicability, maturity, stability, availability, and cost-effectiveness. 


\section{CONTENT}

The tutorial gives an overview of the relevant standards, explains the basis for selecting appropriate techniques, and gives an overview of each method, including some practical exercises.

\section{Standards}

ISO CD 13407 Human centred design processes for interactive systems.

ISO 9241 Ergonomic requirements for office work with visual display terminals. Includes parts 10 to 17 on software ergonomics.

ISO DIS 14598-1 Evaluation of Software Products. Explains how software qualities (including usability) can be specified and measured during development, with the objective of achieving quality in use.

ISO WD 9126-1 Software quality characteristics and metrics. Defines six software quality characteristics (including usability) and quality in use, which is the combined result.

\section{Planning methods}

ISO 13407 gives an overall structure for usercentred design, and includes a checklist of activities required to adhere to the standard, in the following categories: planning, specification of context of use, specification of user and organisational requirements, production and testing of design solutions, and evaluation of designs against user requirements.

Usability Capability Maturity is a means of assessing the maturity of the organisation and identifying where improvements are required.

Usability Context Analysis is a structured method for eliciting and structuring information about the actual or intended Context of Use of an interactive system. The resulting specification of the characteristics of users, tasks, and environment can be used to inform design, and to specify valid and consistent evaluations. This method was originally developed as part of the MUSiC ESPRIT, and has since been developed and refined through commercial application.

\section{Early development methods}

Guides and standards: a method has been developed (by Lloyds Register) which uses the ISO 9241 parts 12-17 dialogue design guidelines as the basis for producing a style guide customised to specific organisational requirements.

Rapid prototyping is a collection of formal and informal techniques for developing, demonstrating and evaluating user interface designs quickly to support rapid iteration early in the design lifecycle. The techniques can be categorised depending on whether the prototypes are passive paper, animated paper or machine, and whether the user interaction with the prototype is naturalistic, prompted by the evaluator or participative design.

Usability inspection methods include inspection by human factors experts ("heuristic evaluation"), by designers, by users or by an appropriate combination. The choice of method depends on the skills available and the potential benefits of involving designers or users in each situation.

\section{Late development methods}

The Performance Measurement Method is a structured technique for delivering meaningful and objective metrics of the performance of the user-system combination in accordance with ISO DIS 9241. The metrics can be used for acceptance criteria, and to compare the performance of alternative designs and products. Originally developed in the MUSiC project, this method has been developed and refined through commercial application

User Satisfaction is a collection of methods for eliciting the subjective opinion of users of an interactive system. These include University College Cork questionnaires SUMI (for office systems), MUMMS (for multi-media) and WAMMI (for web evaluation), and the public-domain SUS, all of which measure user satisfaction as defined in ISO 9241-11.

Conformance to guides and standards including assessing adherence to ISO 9241 parts 13-17.

\section{REFERENCES}

Bevan N (1995) Human-computer interaction standards. In: Anzai \& Ogawa (eds) Proc. 6th International Conference on HCI, July 1995. Elsevier.

Bevan, N (1996) Integrating usability into the development lifecycle. Proceedings of ICAE'96.

Bevan N and Azuma M (1997) Quality in use: Incorporating human factors into the software engineering lifecycle. In Proc. 1977 Internat. Software Engineering Standards Symposium (ISESS'97)

Bevan N, Macleod M (1994) Usability measurement in context. Behaviour and Information Technology, 13, 132-145.

Macleod M, Bowden R, Bevan N and Curson I. (1997) The MUSiC Performance Measurement Method. Behaviour and Information Technol., in publication. 